\title{
A comparative study on the performance of SSDR coreless AFPM generators with conventional and Halbach magnet arrays
}

\author{
Asiful Habib*, Hang Seng Che****, Erwan Sulaiman** and Mahdi Tousizadeh* \\ * Higher Institution Centre of Excellence (HICoE), UM Power Energy Dedicated Advanced Center (UMPEDAC), University of Malaya, \\ Kuala Lumpur, Malaysia \\ ** Research Center for Applied Electromagnetics, Institute of Integrated Engineering, Faculty of Electrical and Electronic Engineering, \\ Universiti Tun Hussein Onn Malaysia (UTHM) 86400 Batu Pahat, Johor, Malaysia. \\ **** Corresponding Author : hsche@um.edu.my
}

Submitted : 17/10/2019

Revised $: 18 / 10 / 2020$

Accepted : 27/10/2020

\begin{abstract}
An axial flux permanent magnet (AFPM) generator is known to be a good candidate for both low- and highspeed applications. In this paper, a comprehensive comparison of four coreless AFPM generators is presented with conventional and Halbach magnet arrangement combined with iron and ironless rotor (epoxy). With the same coreless stator structure, four different AFPM generators with different rotor magnet arrangement and materials are compared in terms of voltage, current, power, machine weight, and power density. The analytical design approach is first presented and is subsequently validated using ANSYS Maxwell electromagnetic finite element analysis (FEA) software. Results show that AFPM machine with fully coreless topology using Halbach array with epoxy rotor can deliver similar power density but has a lower cost compared to conventional magnet array with iron rotor. Hence, this topology is favorable for low power low cost applications.
\end{abstract}

Key words: Axial flux; Coreless; Conventional array; Permanent magnet generator; Halbach array.

\section{INTRODUCTION}

Transition from fossil fuel to renewables has become a global trend and urgency in recent decades due to the non-sustainability of fossil fuel and their detrimental effects to the environment (Zhu et al., 2018). International Energy Agency (IEA) reports that $90 \%$ of the rural electrification, that mostly depends on the off-grid systems, would be powered by renewable energy (Charfi et al., 2018; Mandelli et al., 2016). Among the renewables, hydropower offers an effective and sustainable source of energy due to its technological maturity (Elbatran et al., 2015) and is globally accepted as a better candidate to meet the growing demand for renewable power (Ardizzon et al., 2014). However, environmental concerns about large-scale hydro are escalating due to their substantial carbon footprint; as a result, small-scale hydropower plant, such as pico-hydro is gaining popularity. Pico-hydropower represents the power plants ranging from a few watts up to $5-\mathrm{kW}$. These small-scale power plants are scalable and can run reliably and continuously at very low cost with minimal adverse effect on the environment (Aziz et al., 
2015; ESMAP, 2007). World Bank reports that pico-hydropower is cheaper than other renewable alternatives for off-grid electricity generation (Williamson et al., 2014). A 300-W pico-hydropower unit requires a maximum head of only 1 to 2 meter (ESMAP, 2007). Many experiments have been carried out on various types of water turbines with different speeds for low head pico-hydro applications (Williams, 2000; Williamson et al., 2014). The picohydro turbine speed ranges from 200-900 rpm for low head and comparatively high water flows (Ho-Yan, 2012; Parker, 2017; Singh \& Nestmann, 2009; Williams, 2000; Williamson, 2011). Nowadays pico-hydro machines are user-friendly as they are equipped with power electronics to regulate voltage and balancing the loads (ESMAP, 2007).

On the other hand, axial-flux permanent magnet (AFPM) machines have been employed in a large variety of applications such as hybrid electric vehicles, washing machines, aircraft propulsion, combined heat and power, wind energy generation, portable gensets, starter/alternators, hard disk drive, flywheel energy storage, and wind and pico-hydro turbines (Capponi et al., 2012). In case of pico-hydropower, AFPM offers the benefit of high number of the poles that is befitting for low-speed applications (Chan \& Lai, 2007). AFPM machines with high power density can be obtained with the use of rare earth permanent magnets (PM) (Javadi \& Mirsalim, 2008).

Among different AFPM topologies single-stator double-rotor (SSDR) (Kahourzade et al., 2014) or one stator two rotors (TORUS) configuration offer high efficiency and power density, and better mechanical strength (Mahmoudi et al., 2013). In some applications, it is suggested to have coreless AFPM machines where the stator iron core is replaced by non-magnetic materials such as epoxy (Javadi \& Mirsalim, 2008, 2010; Kahourzade et al., 2014). Being coreless, the machine does not experience eddy current (hence hysteresis losses) and has lower cogging torque. This allows the machine to run at higher efficiency compared to other conventional machines (Javadi \& Mirsalim, 2008). Moreover, the coreless structure reduces the weight of the generator significantly making it portable, which facilitates its deployment. This is particularly important for rural electrification using pico-hydro power where fuel transportation is usually a challenge (Javadi \& Mirsalim, 2008).

In the literature, coreless AFPM machine usually refers to "stator coreless" where ferromagnetic rotor structure is still used in the rotor (Javadi \& Mirsalim, 2008),(Eastham et al., 2002; Fei et al., 2010; Hosseini et al., 2008; Javadi \& Mirsalim, 2010; Minaz \& Çelebi, 2017; Sadeghierad et al., 2009; Tan et al., 2015; Virtic et al., 2008). A fully coreless design, where both rotor and stator uses non-magnetic materials, will significantly reduce the machine weight as well as the production cost. Furthermore, mechanical stresses are also reduced as the machine does not produce attractive forces between the two rotors and stator except between the permanent magnets on the two rotors. However, use of non-magnetic rotor will result in significant flux leakage on the back surface of the rotor and deteriorate performance of the machine (Habib et al., 2020). In this context, Halbach magnet array may provide an interesting solution to this issue by amplifying the magnetic field on the useful side of the rotor while canceling out the magnetic field on its outer side. Several works on the use of Halbach array for AFPM has been presented in (Lee et al., 2004; Praveen et al., 2012; QI et al., 2006; Zhu et al., 2013; Zhu \& Howe, 2001).

It is interesting to compare performances of coreless AFPM machine using combinations of conventional and Halbach magnets with iron and non-iron (epoxy) rotor to underpin the performance of a "fully coreless" AFPM machine compared with the conventional "stator coreless" AFPM. For this purpose, a relatively lower speed of 500 RPM has been chosen that will reduce the number of poles which in turn alleviate the design and fabrication complexity. A comparative study has been carried out in terms of torque, voltage, current, power, weight and power density. For fair comparison, all the topologies are designed with same stator structure, machine diameter and volume of magnets. All the topologies designed with the same analytical equation validated with 3D finite element analysis (FEA) software ANSYS Maxwell. The contents of this paper are organized in the following sequence: fundamental concepts of Halbach and conventional magnet arrangements are explained at the inception followed 
by the fundamental structure of SSDR coreless AFPM and the four topologies presented next; thereafter, analytical calculation is given along with selection of parameters; hence, finite element analysis is presented; performance comparison between the two topologies has been exercised in the next section followed by a summary of the whole work.

\section{CONVENTIONAL AND HALBACH ARRAY}

The arrangement of magnets is an important design criterion for AFPM machine, and two arrangements are considered here: the 'conventional array' and the Halbach array. For conventional array, such as those used in (Khan et al., 2019; Messina et al., 2019; Taran et al., 2018;) the magnets are arranged with alternating north and south poles, either in radial (Figure 1(a)) or tangential direction (Figure 1(b)). The 'Halbach Array' can be considered as a combination of two conventional arrays (radial and tangential), as illustrated in Figure 1(c). The arrangement of the magnet poles in Halbach array helps to strengthen the field in one side of the array while canceling out the field on the other side ( Figure 1(d)) (Zhu et al., 2013).

According to the structure, the two-disc rotors associated with magnets have an axial gap between them to fit the coil with an optimized physical gap between the magnet discs. Normally iron core rotors enhance the magnetic field and as a result, higher air gap magnetic flux density leads to higher power. In the case of a conventional array, the magnetic field is active on both side of the array and the use of epoxy for the rotors leaves one side of the field unused. That is why for conventional array iron core rotors are preferable for an AFPM machine.

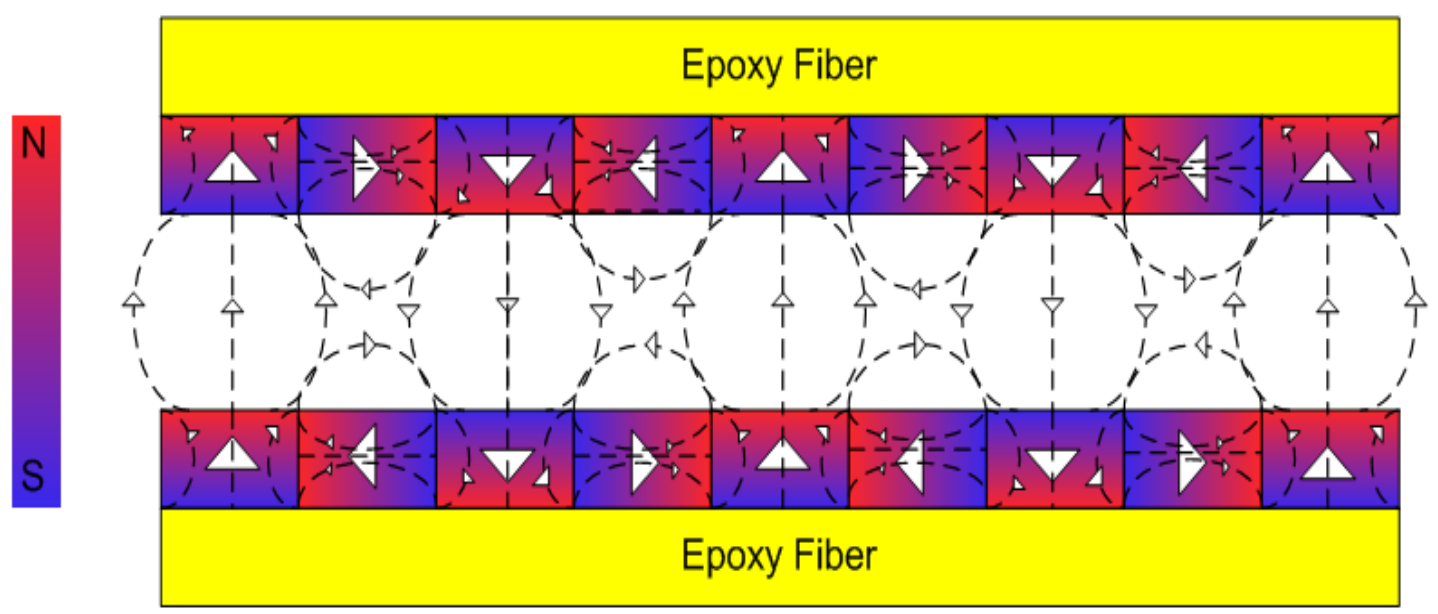

Figure. 1. Schematic of conventional and Halbach array flux pattern 


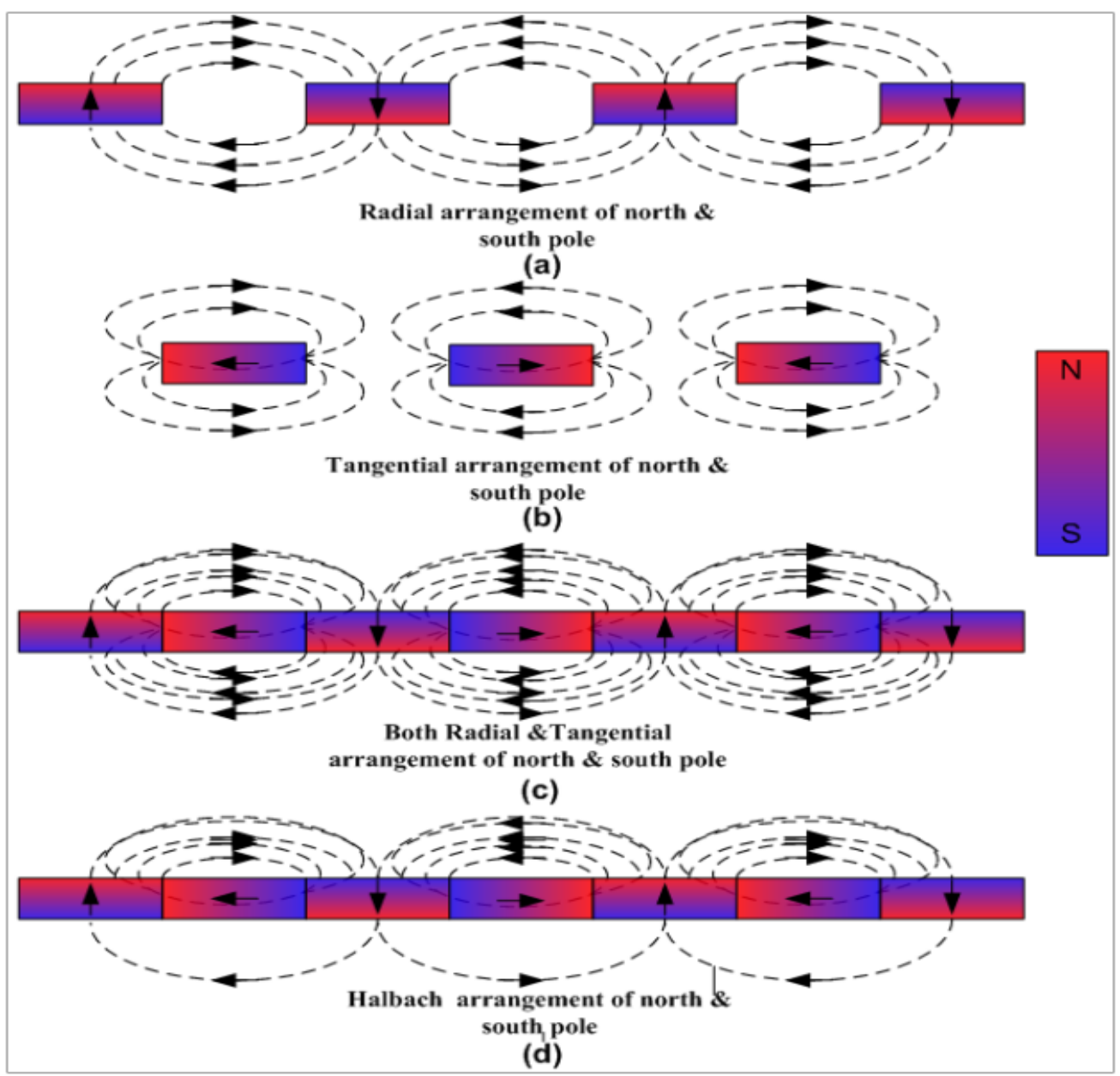

Figure. 2. Schematic side view of magnet poles with an opposite arrangement (N-S type) in Halbach array

In the case of a conventional array, the magnetic field is active on both side of the array and the use of epoxy for the rotors leaves one side of the field unused. That is why for conventional array iron core rotors are preferable for an AFPM machine.

For ironless rotor structure, Halbach array can be useful by cancelling out the fluxes on the back of the rotor and strengthen up the field to the active side of the array, thus help to obtain high magnetic flux density in the air gap that leads to the high power density (Gieras et al., 2008). Figure 2 shows the schematic of rotor poles with an opposite arrangement (N-S type) and the associated flux paths for the Halbach epoxy rotor generator. The epoxy materials used in stator and rotor are temperature and pressure resistant. Apart from that, the pole pair formation due to magnets is different from one another. In conventional array, two magnets create one pole, whereas in Halbach array four magnets create one pole. Figure 3 shows the pole pair wavelength $\left(l_{a}\right)$ of both arrays. Here magnet width to pole pitch ratio $\left(a_{P}\right)$ defines the gap between the magnets. For conventional array an optimum gap $\left(a_{P}\right)$ between the magnets is necessary to get a high air-gap magnetic flux, on the other hand for Halbach array to strengthen the field in one side of the array, the gap $\left(a_{P}\right)$ should be as less as possible. 

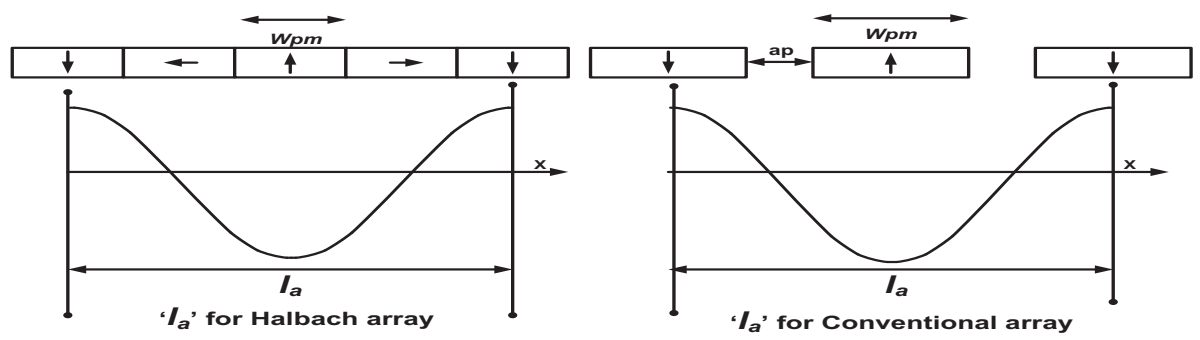

Figure 3. Schematic of pole pair wavelength Halbach (left) and conventional (right)

\section{MODELING AND DESIGN}

The SSDR coreless AFPM machine has a single internal coreless stator between two external PM rotor discs. The stator coils are single layer concentrated windings of trapezoidal geometry, embedded in an epoxy, and covered with composite material hardener to ensure sufficient mechanical strength to the whole structure of the stator. The rotor structure is formed by trapezoidal shape magnets, rotor core, and shaft. The two discs shaped rotor carry the axially magnetized $\mathrm{NdFeB}$ magnets mounted axially on the inner surfaces of the two rotor discs. NS type Flux direction is traveled axially from one rotor disc to another rotor disc via the coreless stator.

Conventional magnet array

Halbach magnet array

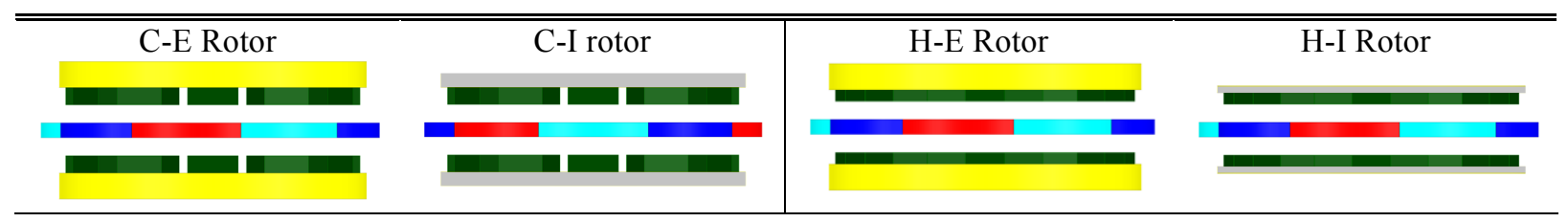

Epoxy Iron $\square$ Magnet $\square$ Coreless Stator Coils $(\mathrm{a}, \mathrm{b}, \mathrm{c})$

Figure 4. Centre aligned side view of the four different generators for overall comparison

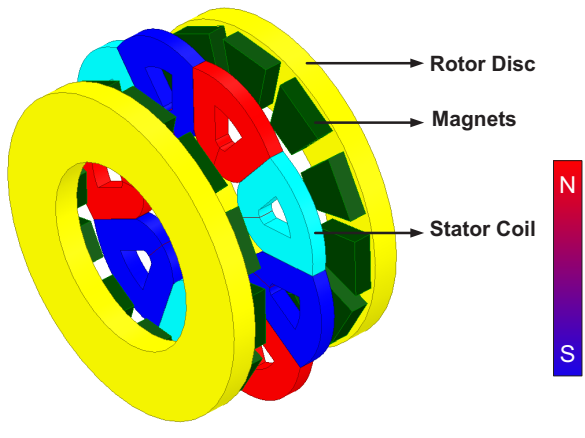

(a)

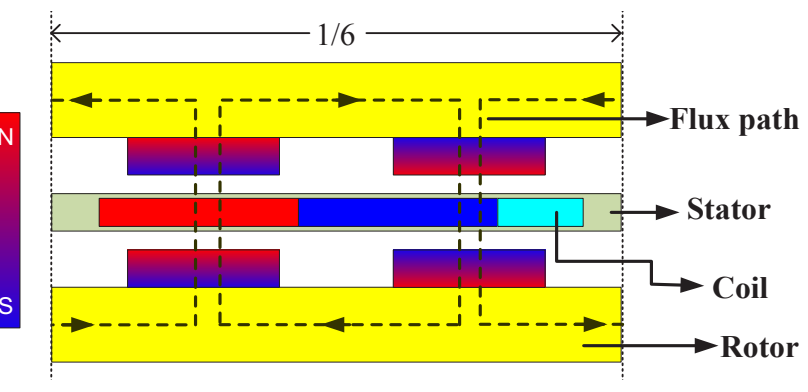

(b)

Figure 5. The design of three-phase conventional SSDR AFPM machine. (a) complete model for conventional (b) flux path (NS type) in $1 / 6$ of the design. 
The gap between the rotor and stator are kept at $0.5 \mathrm{~mm}$ on both sides. Figure 5 shows the complete model and the flux path for the conventional magnet array. In the present research, four different SSDR coreless axial flux permanent magnet (AFPM) generator have been designed with the same parameters for comparison. The two different magnet arrangements (Conventional and Halbach), are combined with two different materials (iron and epoxy) of the rotor, to give the following four topologies:

i) Conventional magnet array with iron rotor (C-I Rotor)

ii) Conventional magnet array with epoxy rotor (C-E Rotor)

iii) Halbach magnet array with iron rotor (H-I Rotor)

iv) Halbach magnet array with epoxy rotor (H-E Rotor)

The major difference among the four topologies lies in the arrangement of the magnets and disparity of materials for the rotor discs. The difference is shown clearly in Figure 4 and 6 . The four topologies all have 12 poles, for a speed of $500 \mathrm{rpm}$ at $50 \mathrm{~Hz}$.

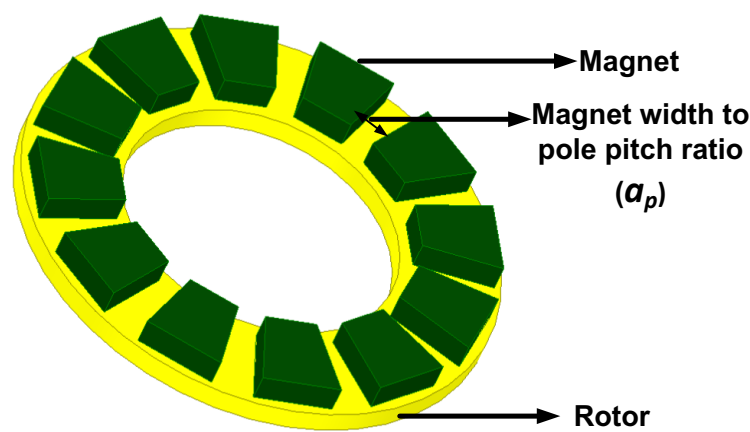

C-I \& C-E Rotor

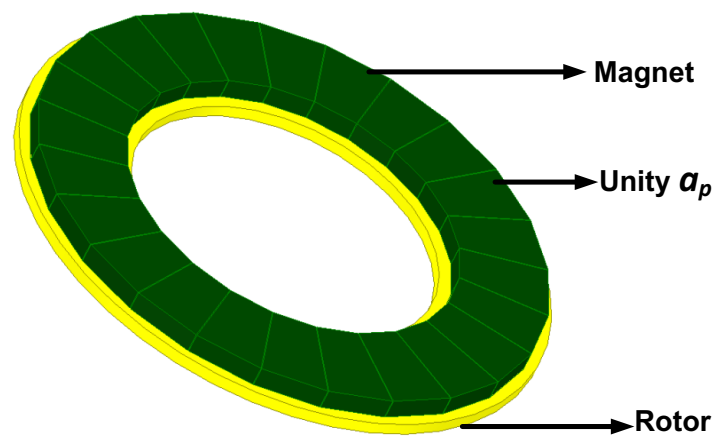

H-I \& H-E Rotor

Figure 6. Rotor with conventional (C-I Rotor, C-E Rotor) and Halbach (H-I Rotor and H-E Rotor) magnet arrays.

Though conventional and Halbach arrays have different magnet width due to 'magnet width to pole pitch ratio', their magnet thickness is different such that the total volume of magnets (hence the magnet cost) is kept constant for all four topologies. The common input parameters for the four topologies are shown in Table 1. 
Table 1. Commoninput parameters for all four topologies

\begin{tabular}{|c|c|c|c|c|}
\hline & & Parameter Name & Unit & Value \\
\hline \multirow{11}{*}{ 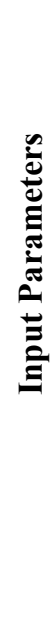 } & \multirow{4}{*}{ 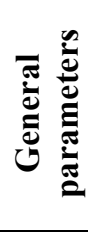 } & Number of Pole $(P)$ & - & 12 \\
\hline & & Number of Coil $(C)$ & - & 9 \\
\hline & & Rotational Speed $(\omega)$ & $\mathrm{rpm}$ & 500 \\
\hline & & No of Turn per Coil $\left(N_{C}\right)$ & - & 250 \\
\hline & \multirow{7}{*}{ 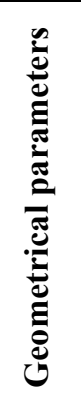 } & Ratio of Inner \& Outer & - & 0.577 \\
\hline & & Outer Diameter $\left(D_{o}\right)$ & $\mathrm{mm}$ & 180 \\
\hline & & Inner Diameter $\left(D_{i}\right)$ & $\mathrm{mm}$ & 104 \\
\hline & & Magnet Length $\left(M_{L}\right)$ & $\mathrm{mm}$ & 30 \\
\hline & & Total Magnet Volume $\left(M_{V}\right)$ & $\mathrm{mm}^{3}$ & $176.652 \mathrm{e}^{3}$ \\
\hline & & Coil Axial thickness $\left(C_{h}\right)$ & $\mathrm{mm}$ & 8.5 \\
\hline & & Coil Bandwidth $\left(C_{B W}\right)$ & $\mathrm{mm}$ & 17 \\
\hline
\end{tabular}

\section{ANALYTICAL DESIGN OF AFPM GENERATOR}

For analytical design, some inceptive design assumptions based on sizing equations are necessary. The parameters for initial design are the phase number $(m)$, output power $\left(P_{o}\right)$, speed $\left(\omega_{S}\right)$, magnetic loading $\left(B_{g}\right)$, electrical loading $\left(A_{m}\right)$, ratio of inner and outer diameter $(\lambda)$, power factor $(\cos \varphi)$ where the values are given in Table I. For machine design, the main parameter to be decided first is diameter $\left(D_{\text {out }}\right)$. Based on the sizing equation the $D_{\text {out }}$ can be determined as equation (1) (Huang et al., 1999; Mahmoudi et al., 2013):

$$
D_{\text {out }}=\left(\frac{p_{0}}{\frac{\pi}{2} K_{\text {size }} B_{g} A_{m} \eta \frac{f}{p}\left(1-\lambda^{2}\right)\left(\frac{1+\lambda}{2}\right)}\right)^{\frac{1}{3}}
$$

where, $K_{\text {size }}=k_{e} \cdot k_{i} \cdot k_{p}$. For sinusoidal waveform, the values of $k_{e}, k_{i}, k_{p}$ are briefly explained in (Huang et al., 1999; Mahmoudi et al., 2013) where maximum parameter's value required in equation (1) comes from the very initial assumption. The air gap magnetic flux density $B_{g}$ is normally dependent on the magnet geometry as well as magnet grade.

The ratio of inner and outer diameter $(\lambda)$ is considered as another important parameter for AFPM machine design in maximizing the output power. From previous research, optimized values of $\lambda$ were chosen for different AFPM design, out of which, $1 / \sqrt{3}$ and $1 / \sqrt{2} .5$ are common for the most of the configurations (Chan \& Lai, 2007; Daghigh et al., 2017; Upadhyay \& Rajagopal, 2006). In the present study, the value of $\lambda$ is chosen $1 / \sqrt{ } 3$, for getting maximum power. The rotating speed $\omega_{S}$ is used to determine the pole number using equation (2) and from pole number, the coil number can be easily determined by equation (3). 


$$
\begin{aligned}
& \omega_{S}=\frac{120 f}{p} \\
& Q=\frac{3}{4} \times p
\end{aligned}
$$

where $f$ is the frequency, $p$ is the pole number and $Q$ is the number of the coil. The electrical loading $\left(A_{m}\right)$ is used for the sizing equation (4)(Huang et al., 1999).

$$
A_{m}=4 m N_{c p h}{ }_{p h} / \pi D_{o u t}(1+\lambda)
$$

where Ncph is the number of conductors per phase Iph is the current per phase. From equation (4) Nc can be determined as,

$$
N_{c}=\frac{\pi \alpha_{w} D_{o u t}(1+\lambda) A_{m}}{4 Q I}
$$

where $a_{w}$ is the number of parallel current paths.

\section{Magnet Geometry}

(6)

The air gap magnetic flux density $B_{g}$ and PM axial height $h_{p m}$ has a strong contribution as shown in equation

$$
h_{p m}=\frac{\mu_{m} B_{g}\left(L_{s c}+2 g\right)}{2\left(0.9 B_{r}-\frac{B_{g}}{K_{p m}}\right)}
$$

where $\mu_{m}$ is the magnet permeability, $B_{r}$ is PM residual flux density, $g$ is the air gap length and $K_{p m}$ is PM leakage flux factor. As the machine is pure coreless the inner and outer diameter is actually the magnet outer and inner diameter. In this case, the magnet has a trapezoidal shape and is defined by the inner and outer magnet width as shown in Figure 7 . The outer magnet width $\left(w_{p m o}\right)$, inner magnet width $\left(w_{p m i}\right)$ and magnet length $\left(l_{p m}\right)$ can be calculated as,

$$
w_{p m o}=\frac{2 \pi r_{o}-\left(n_{M} \alpha_{p}\right)}{n_{M}}
$$




$$
\begin{gathered}
w_{p m i}=\frac{2 \pi r_{i}-\left(n_{M} \alpha_{p}\right)}{n_{M}} \\
l_{p m}=w_{p m o}-w_{p m i}
\end{gathered}
$$

where $n_{M}$ is the total number of the magnet.

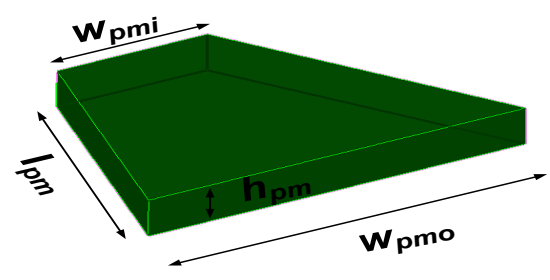

Figure 7. Schematic geometry of magnet

\section{Air Gap Magnetic Flux}

The main difference between the Halbach and conventional array is on the magnetic flux density and distribution, as explained before. Geometry and other parameters can be kept the same for better comparison except for the magnet size. For the different characteristics of the two topologies, the size of the magnet cannot be the same for a fixed rotor diameter. The number of magnets used for Halbach configuration is double that of the conventional array. In order to maintain the same total magnet volume, the axial heights of the magnets are adjusted while the magnet length was kept constant for both. Though the wavelengths are same for the both conventional and Halbach, they have different effect for magnet width to pole pitch ratio $\left(a_{P}\right)$. For conventional rotor, optimal $a_{P}$ is required for less torque ripple with maximum average torque (Kim et al., 2007). On the other hand, Halbach rotor needs to minimize the gap between magnets $\left(a_{P}=1\right)$ to ensure effective cancelling of magnetic field on one side and the strengthening of flux on the other side. Thus there are two different equations for calculating $B_{g}$. The equations of the air gap magnetic flux density of Halbach array and conventional array can be written as equation (10) and equation (14).

$$
B g(h)=B r\left[1-\exp \left(-\beta h_{p m}\right)\right] \frac{\sin \left(\pi / n_{M l}\right)}{\pi / n_{M l}}
$$

Where $\beta$ is the $2 \pi / l_{a}$ and $l_{a}$ is the spatial period (wavelength) of the array, $n_{M l}$ is the number of magnets per wavelength. For $l_{a}$ the value differs for the two different topologies of Halbach array and conventional array. For Halbach array, four magnets create one full wavelength or one pole pair as there is no gap between the magnets, refer to equation (11). In Figure 3 the schematic is shown for $l_{a}$ (Gieras et al., 2008). 


$$
l_{a}=4 w_{p m}
$$

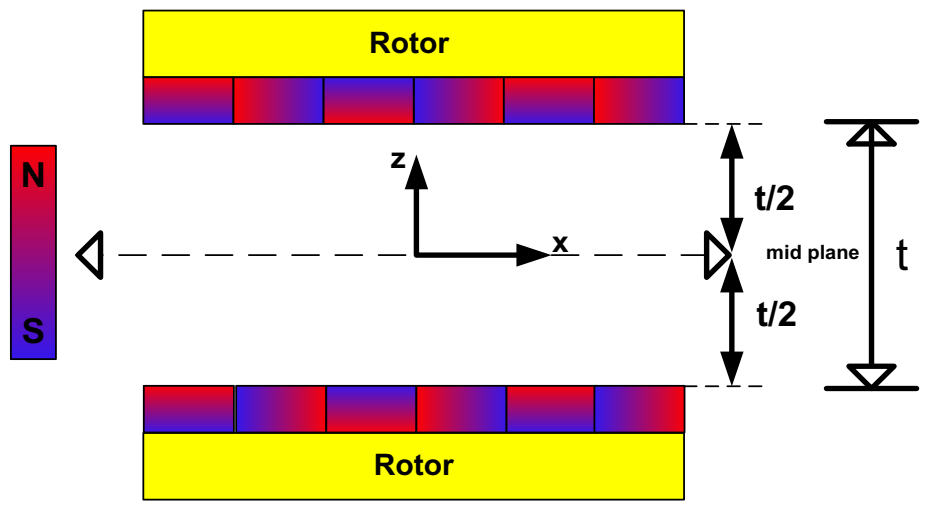

Figure 8. Plane region for air-gap magnetic flux density

From equation (10) the peak value of magnetic flux density at the active surface of Halbach array can be calculated. As seen in Figure 8, the tangential and normal component of the magnetic flux in the space between two discs are given by equation (12) and equation (13) (Gieras et al., 2008)

$$
\begin{aligned}
& B_{x}(x, z)=B_{g} \frac{1}{\beta} \cos (\beta x) \frac{2 \sinh (B z)}{\exp (\beta t / 2)} \\
& B_{z}(x, z)=B_{g} \sin (\beta x) \frac{2 \cosh (B z)}{\exp (\beta t / 2)}
\end{aligned}
$$

where $B_{x}$ is the tangential component (along the x-axis), $B_{z}$ is the normal component (along z-axis). For the proposed design the significance of normal component is higher as the design is dual disc rotor topology of axial flux machine. Briefly, the value of $B_{z}$ is minimum in the -middle of the two rotor discs and closer to the magnets the value becomes maximum.

For conventional array the equation (Virtič et al., 2016) is given by

$$
B_{g}(c)=\frac{1}{\mu_{0}} \int_{S} r B_{x} B_{z} d S
$$

where $\mu_{0}$ is the permeability of free space, $r$ is the radius of the rotor, $S$ is the integration surface of the mid plane of the air gap. $B_{x}$ and $B_{z}$ depend on the optimized geometry of the machine parameter, like $a_{P}$.

For this paper, (12) and (13) are used for calculating the air gap flux for the rotor with Halbach array while (14) is used for rotor with conventional magnet array. 


\section{Stator Coil Geometry}

For higher efficiency and lower cost, non-overlapping concentrated windings have been used since it needs less volume of copper which reduces the copper losses and increases generator efficiency. In this design single layer trapezoidal coil shape is chosen for shortening the end winding length $\left(l_{e}\right)$ as compared to active coil length $\left(l_{a c t}\right)$ of the coil that helps to maximize the coil flux linkage. A shorter le reduce the resistive losses in the inactive part of the coil. The calculation of $l_{e}$ and $w_{c}$ have been done with equations (22) and (23) respectively (Rossouw, 2009). Figure 9 shows the schematic of the coil geometry. On the other hand, only the stator coil axial height $\left(L_{S c}\right)$ and coil cross-section area $\left(S_{w}\right)$ is considered because the coil height has an impact on the geometry of the axial height of the machine via the air-gap length from magnet associated rotor disk to another side of the rotor disk. An optimized $L_{S C}$ is required for higher output power. A large $L_{S C}$ increases the total air-gap length as well as the active area length of the magnetic flux density and finally will decrease the magnetic flux density in the air gap. On the other hand, very short axial length will require a higher $S_{w}$ in a result large width of coil $w_{c}$. For a fixed diameter the high $w_{c}$ increases the difficulty to fit all the coils in the limited circular space. The $L_{S c}$ and $S_{w}$ can be obtained as follows:

$$
\begin{gathered}
S_{w}=\frac{2 I p h^{N} c}{K_{f^{a}{ }_{w} a}} \\
L_{S c}=\frac{2 S_{w} Q}{k_{S} \pi D_{i n}}
\end{gathered}
$$

where $K_{f}$ is the fill factor, $J_{a}$ is the current density, and $k_{S}$ is the space utilization factor. For coil wounding, $K_{f}$ is an important factor as it signifies the cross-section of the coil $S_{w}$. As a rule of thumb, the value of $K_{f}$ for manually constructed winding with circular cross section is around 0.55 to 0.78 (Latoufis et al., 2012). The factor $k_{S}$ is related to the mechanical strength of the stator structure. The coreless structure should be mechanically strong enough to hold the coils and against the attraction of magnets. Winding factor $\left(K_{w}\right)$ is another important parameter for the coil design as well as the total torque and the power, which is typically a value between $0.9 \leq K_{w} \leq 1$ (Kamper et al., 2008).

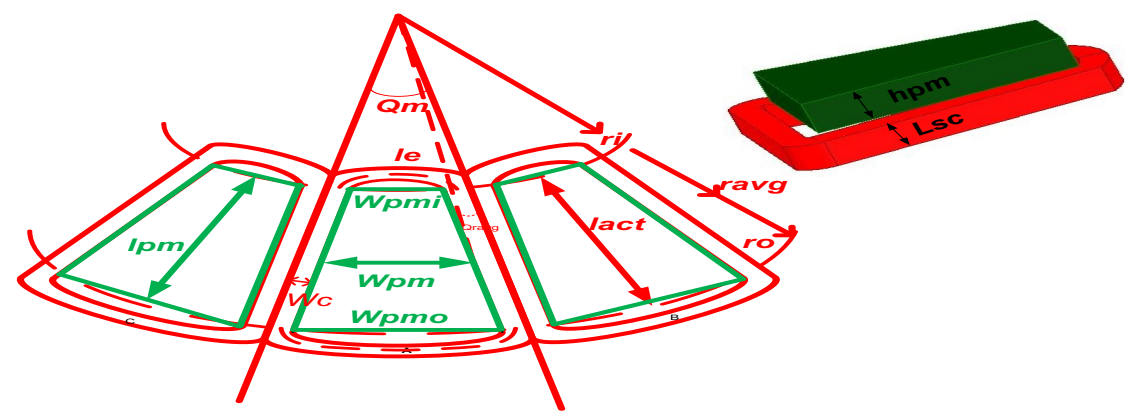

Figure 9. Schematic of coreless non-overlapping winding and 3D geometry of magnet (green color) and coil (red color) together with their position in the machine. 


\section{Induced Voltage}

The induced voltage calculation is dependent on coil geometry and placement. The RMS value of sinusoidal phase voltage of non-overlapping winding $E_{v}$ can be determined by (17) (Kamper et al., 2008).

$$
E_{v}=\frac{q_{p}}{a_{w}} \frac{2 \sqrt{2}}{p} w_{S} B_{g p} N_{c} r_{a v g} l_{a c t} k_{p} k_{d}
$$

where $q_{p}$ is the number of stator coils per phase, $B_{g p}$ is the peak air-gap flux density, $r_{a v g}$ is the average radius of the stator winding, $l_{a c t}$ is the active length of the coil, $k_{p}$ is the pitch factor of the non-overlapping winding and $k_{d}$ is the distribution factor. The Pitch factor $k_{P}$ and the distribution factor $k_{d}$ can be calculated by equation (18) (Rossouw, 2009). In Figure 9, $r_{a v g}$ and $\theta_{m}, \theta_{\text {avg }}$ are shown.

$$
\begin{gathered}
k_{p}=\frac{\sin \left(\theta_{m} \frac{[1-\kappa]}{2} \sin \left(\frac{\kappa \theta_{m}}{2}\right)\right.}{\frac{\kappa \theta_{m}}{2}} \\
\text { where } \theta_{m}=\frac{\pi p}{Q} \text { and } \kappa=\frac{\theta_{r_{a v g}}}{\theta_{m}} \\
k_{d}=\frac{\sin \left(n \frac{\left[\theta_{m}-\pi\right]}{2}\right)}{n \sin \left(\frac{\left[\theta_{m}-\pi\right]}{2}\right)}
\end{gathered}
$$

\section{Magnetic Pull on Rotor Dises}

In a SSDR AFPM generator there exist magnetic pull between the two rotors which exerts mechanical stress to the structure. For ironless rotor, this magnetic pull is due to the magnetic attractions between the magnets, while for the case of iron rotor; additional attraction exists between the magnets and the iron rotors.

The attraction force due to two magnets placing in a distance of ' $g$ ' apart, with a magnet surface area of $S_{P M}$, a magnet thickness of $h_{p m}$ and an air-gap magnetic flux density $B_{g}$ can be expressed as follows in equation (20):

$$
F=\frac{2 . B_{g}{ }^{2}{ }_{p m}{ }^{2} S_{P M}}{\mu_{0} g^{2}}
$$




\section{SELECTION OF DESIGN PARAMETERS AND FINITE ELEMENT ANALYSIS}

For selections of resistive load for same machine loading, rotor thickness in terms of $B_{g}$, leakage flux and mechanical deflection of the rotor, have been analyzed and examined the four topologies. In order to minimize cost and the size, the rotor should be as thin as possible but thick enough to ensure no significant leakage flux appear on the external surface of the rotor. For iron rotor, air-gap magnetic flux density depends on the rotor thickness, as thin rotor will result in flux saturation which reduces the flux density. Sufficient thickness is also important to give sufficient mechanical strength such that the magnetic attraction force between the two rotors will not cause significant mechanical deflection of the rotors. The electromagnetic and mechanical tests are analyzed using ANSYS Maxwell and Auto-CAD Mechanical design software, respectively. The whole design process is presented in Figure 10.

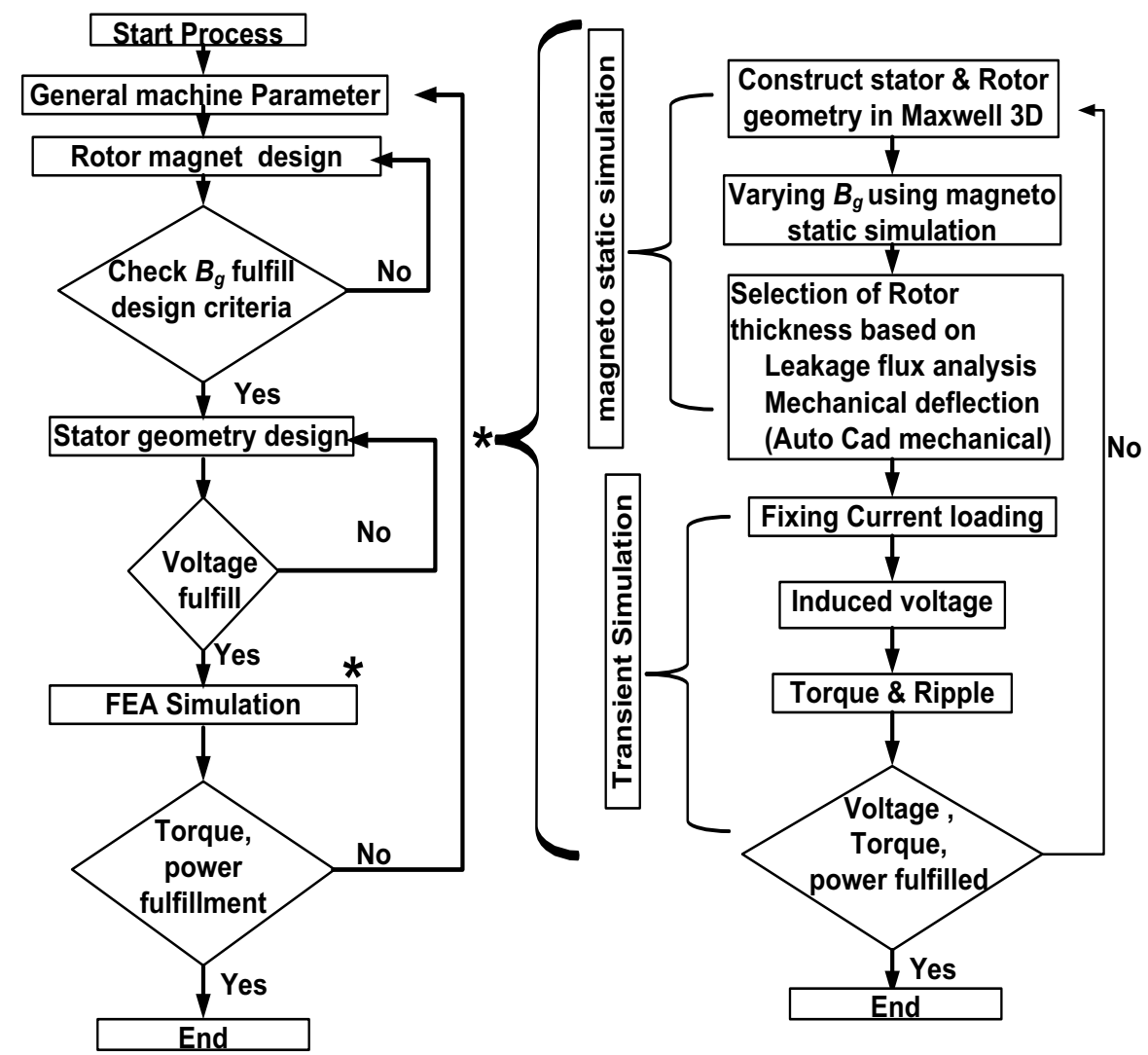

Figure 10. Flow chart of the design process

\section{Selection of Resistive Load for Same Machine Loading}

In order to make a fair comparison of the different rotors and the magnet arrangements the designs need to fix a same current loading for all the stator of different machine. As the geometry and the number of conductors of the stator coil for all the different machine are same, a fixed current is used by choosing different loading. From the wire gauge conductor size, AWG-16 is used for this design which is chosen according to the coil geometry and 
conductor number. The maximum current carrying by AWG-16 is 3.7 A. Thus 5.23A peak current or RMS 3.7A is fixed for all the stator electrical loading. To identify the different loading for different machines a test is conducted in Figure 11 and Figure 12 by fixing the current for all the four machines.
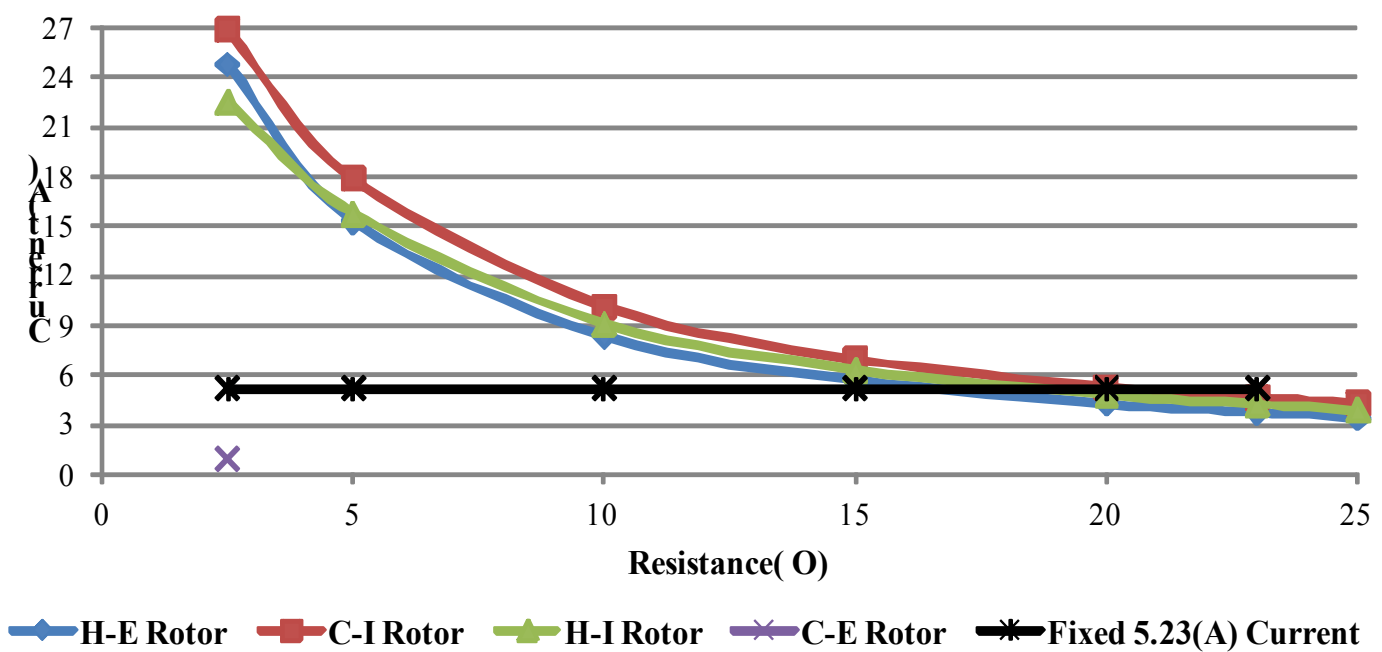

Figure 11. Current vs. different loading test.

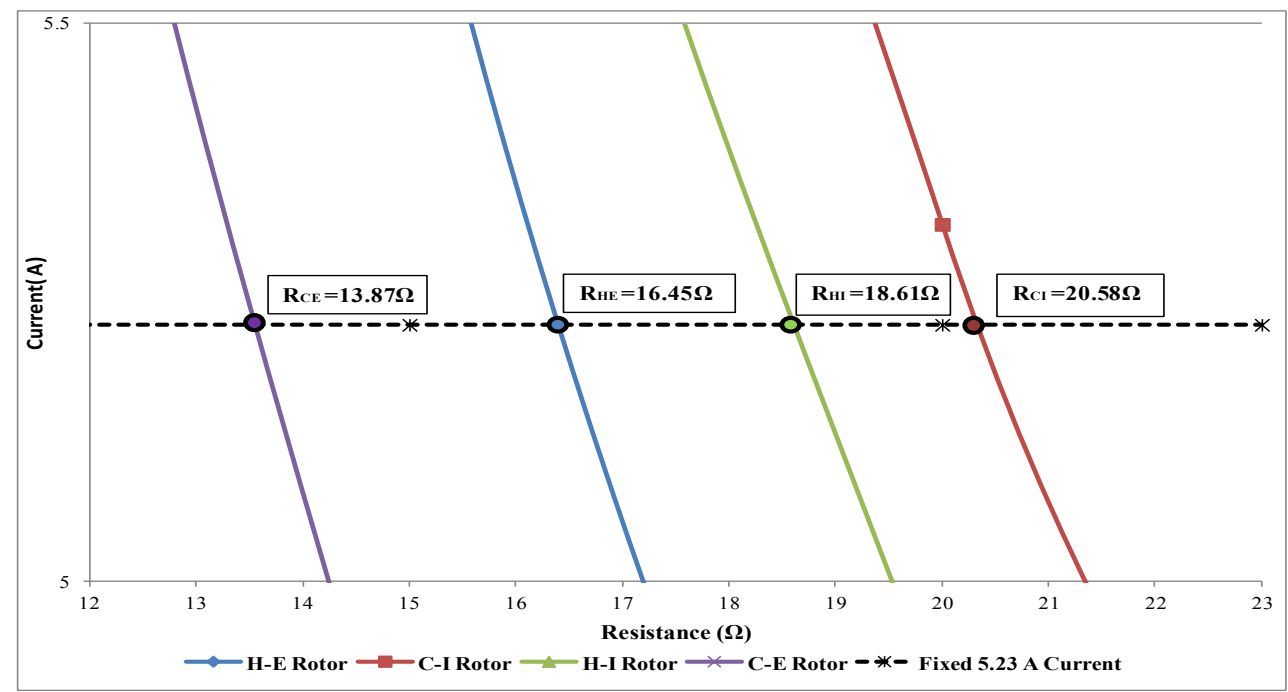

Figure 12. Current vs. different loading test (zoom in image).

\section{Selection of Rotor Thickness}

The rotor thickness selection depends on three important parameters which have direct effect to the rotor thickness. They are air gap magnetic flux density $\left(B_{g}\right)$, leakage flux and mechanical deflection of rotor. 


\section{Airgap Magnetic Flux Density vs. Rotor Thickness:}

The magnetic flux density $\left(B_{\mathrm{g}}\right)$ is the function of iron rotor thickness. As the relative permeability of the ferromagnetic material follows the B-H curve so the material should have a saturation point for magnetic flux. Figure 13 shows the variation of $B_{\mathrm{g}}$ with respect to iron rotor thickness. From the figure, the air-gap magnetic flux increases with the increase of rotor thickness up to a saturation point, beyond which further increasing rotor thickness does not increase the flux. From the FEA analysis, it can be seen that saturation occurs earlier for Halbach array then conventional array. This indicates that Halbach rotor requires thinner rotor to maximize the air-gap flux. However, if the rotor thickness is allowed to increase further, conventional magnet array is able to give higher airgap flux for the same magnet volume.

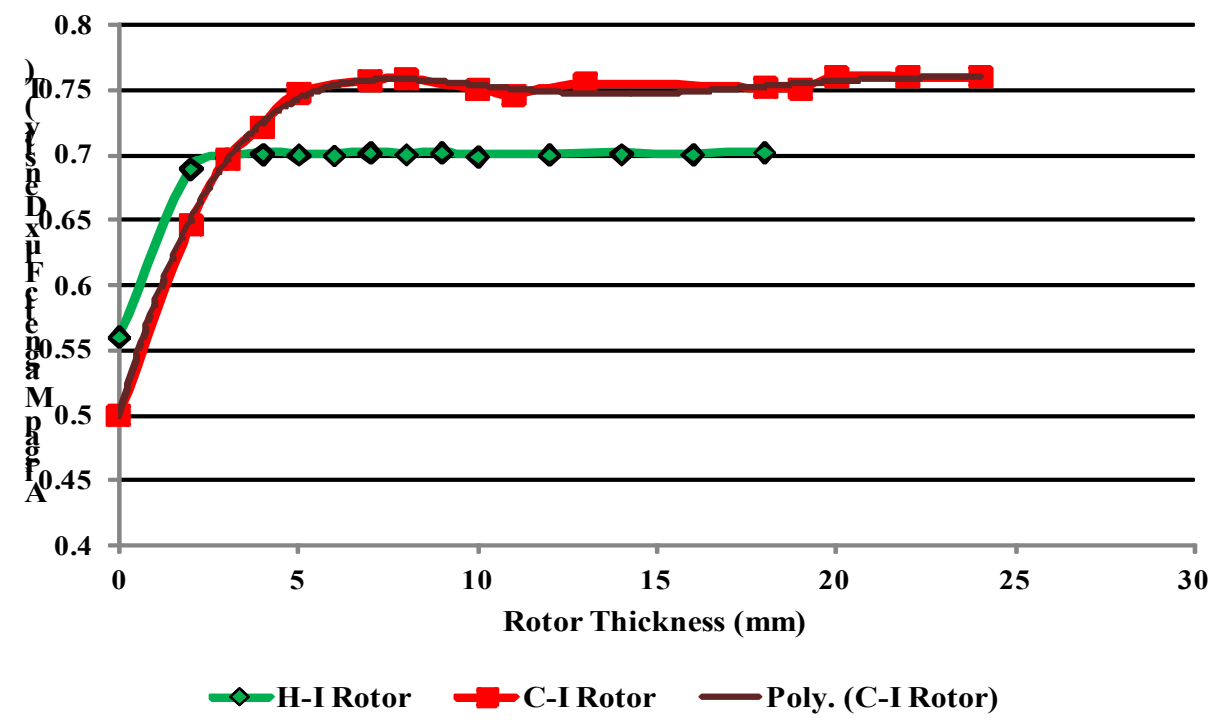

Figure 13. Iron rotor thickness vs. air-gap magnetic flux density of conventional and Halbach array machine.

\section{Leakage Flux Analysis:}

Apart from $B_{g}$, the rotor back iron should also be thick enough to ensure no significant leakage flux. The leakage flux is tested on a distance of $0.01 \mathrm{~mm}$ from the rotor upper surface of the four topologies. The test has been done in ANSYS Maxwell magneto-static solution. A line is drawn at a distance of $0.01 \mathrm{~mm}$ from the rotor upper surface and simulated for all four topologies with various thicknesses. In Figure 14, leakage flux with rotor thickness variation is shown. Halbach rotor has lower leakage flux than the conventional rotor, due to flux cancellation effect. Halbach array requires much lower rotor thickness (around $2 \mathrm{~mm}$ ) to reduce leakage flux to a negligible range, than conventional array (around $7 \mathrm{~mm}$ ). 


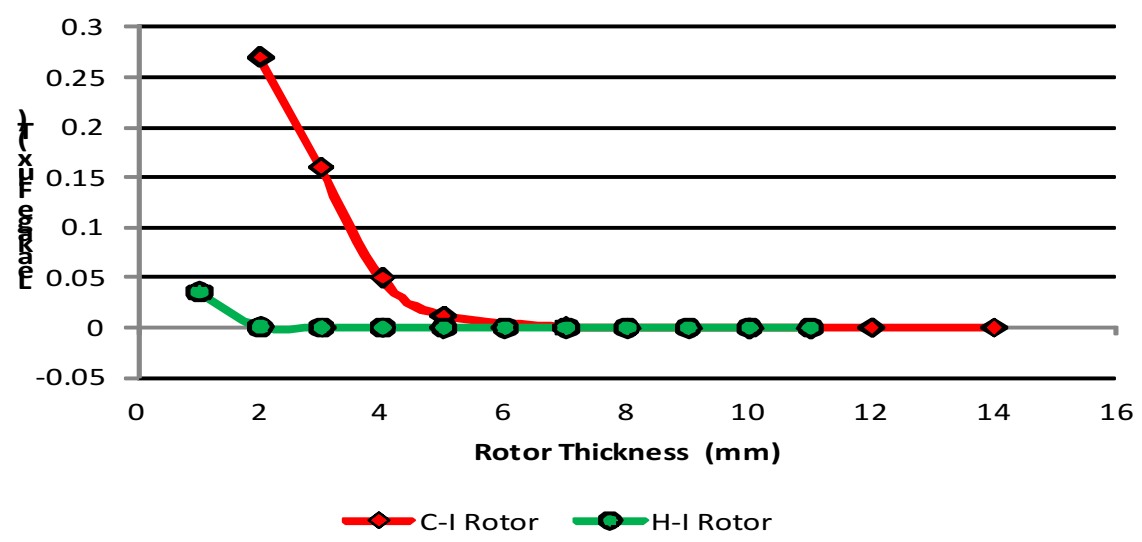

Figure 14. Iron rotor thickness vs. leakage flux of conventional and Halbacharray machine

\section{Analysis of Mechanical Deflection of Rotor}

For the construction of the SSDR AFPM machine, the two opposite rotors attached with magnets are attracted to each other. Although attraction force works for both ferromagnetic and non-ferromagnetic rotor, for nonferromagnetic rotor it is slightly less. The strong attraction force between the magnets imposes an opposite pulling force on the rotor that tends to bend the rotor structure leading to a collision between the rotor and stator or can reduce the air-gap distance between them; as a result, a non-uniform and unbalanced magnetic flux density will be formed in the air-gap. Hence, mechanical deflection is another important point of consideration to design optimum rotor thickness for the four topologies. Equation (20) is showing the force calculation for the magnetic pull on rotor discs. To find an optimum thickness of the rotor, the force is applied to the various thickness of the rotor for both ferromagnetic and non-ferromagnetic material. Figure 15 shows the deflection of the rotor from Von Mises stress analysis for the four topologies, while Figure 16 shows the particular Von Mises test result from the AutoCAD Mechanical.

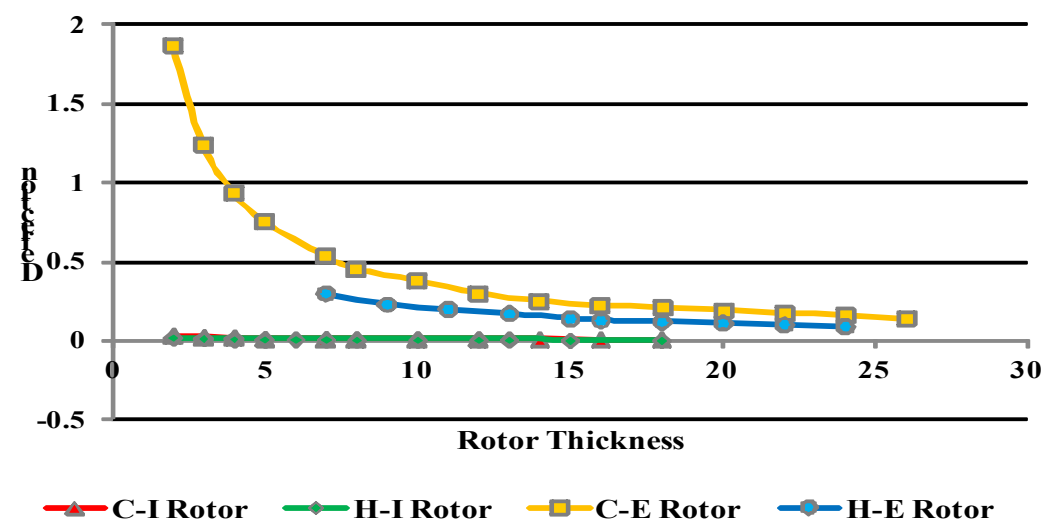

Figure 15. Mechanical deflection $(\mathrm{mm})$ of rotor vs. rotor thickness $(\mathrm{mm})$ for four different topologies 

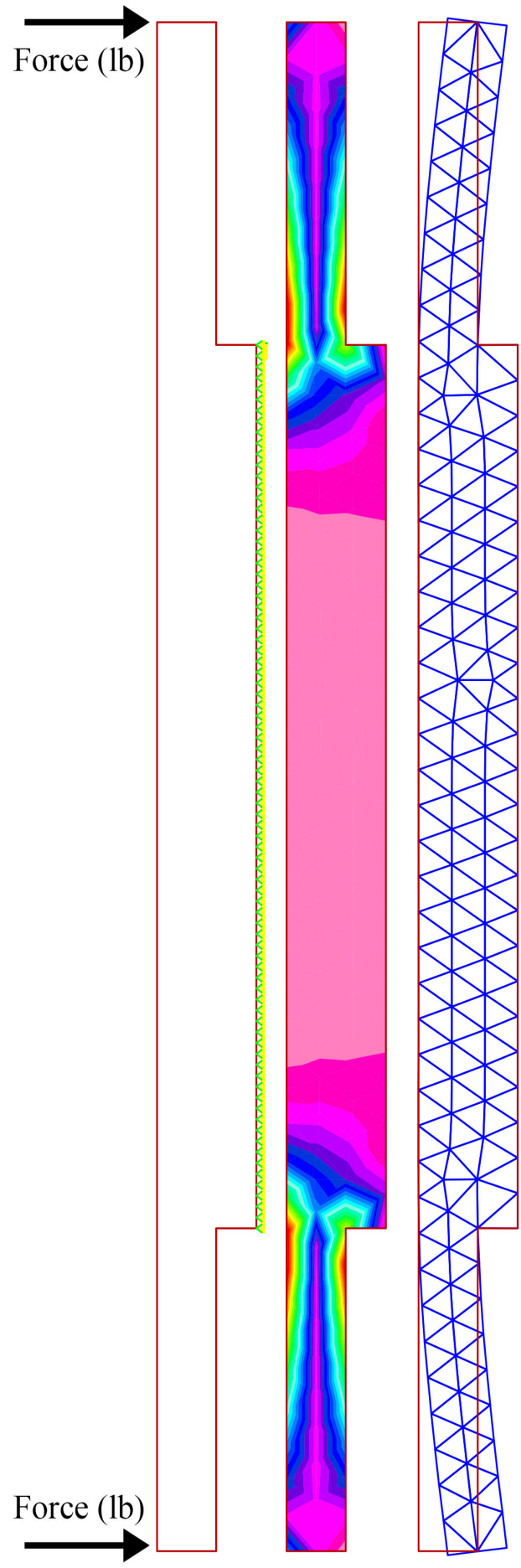

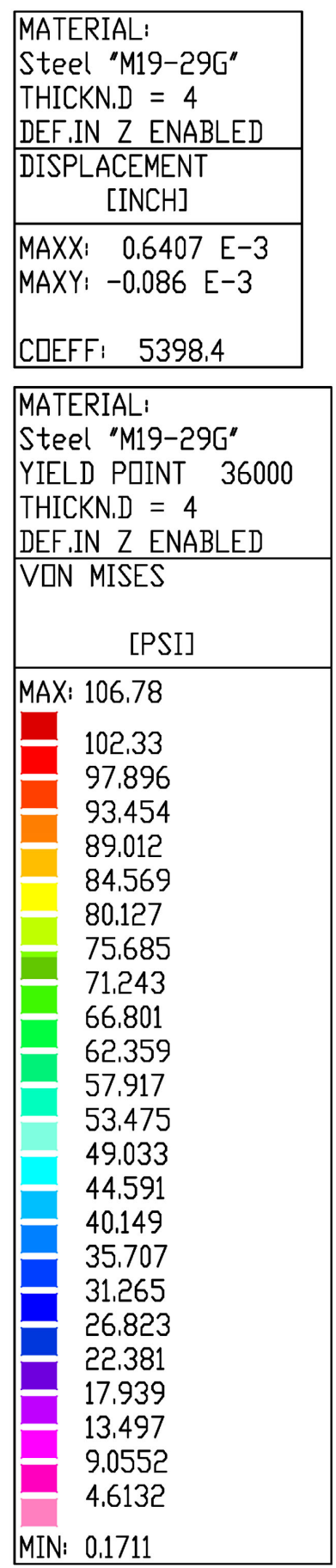

Figure 16. Stress test results using Von Mises method in AutoCAD Mechanical for the $4 \mathrm{~mm}$ C-I Rotor. 
It is evident that deflection is higher in non-ferromagnetic rotor compared with ferromagnetic material. Thus, to ensure the deflection is within the acceptable range, the thickness of non-ferromagnetic rotor should be greater than that of the ferromagnetic one. According to the Figure 15, the thickness of $8 \mathrm{~mm}$ and $4 \mathrm{~mm}$ is chosen for C-I and $\mathrm{H}-\mathrm{I}$ Rotor respectively that comes with negligible deflection values which is $10 \%$ of allowable bending. On the other hand, with the maximum allowed deflection of $0.2 \mathrm{~mm}$, the thickness of the C-E and H-E Rotor are selected to be 18 and $10 \mathrm{~mm}$ respectively which is safe bending for the epoxy rotors. A few simulations are performed for all four generators which come with optimized rotor thickness in accordance with magnetic flux density $B_{g}$, leakage flux and the rotor mechanical deflection. From the FEA results the magnetic flux density in the air gap, voltage, current, torque is taken as output results for ranking the performance of every single generator. Figures. 17, 18, and 19 show the voltage, current, average torque and torque ripple for the four different generators: C-E Rotor, C-I Rotor, H-E Rotor and H-I Rotor. Air gap flux densities at the middle of the two rotors are shown in Figure 20. All the four generators are found to be able to deliver sinusoidal voltage and current which is expected from a three-phase generator. Here it is important to mention that the current waveform for the four generators are overlapping each other because of the same electrical loading

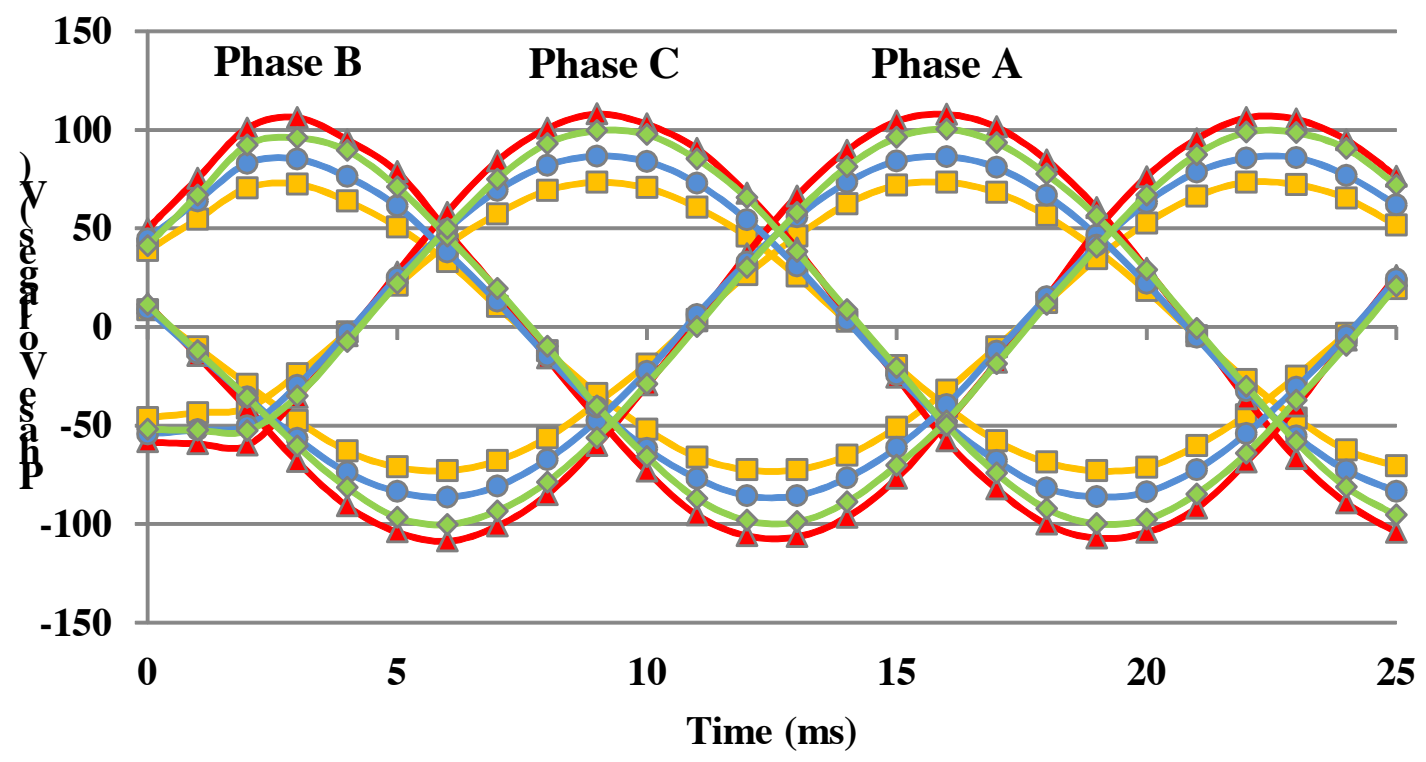

$\neg-$ C-E Rotor $\rightarrow$ C-I Rotor $\multimap-$ H-E Rotor $\multimap-$ H-I Rotor

Figure 17. Voltage waveforms from the FEA analysis for C-E Rotor, C-I Rotor, H-E Rotor and H-I Rotor 


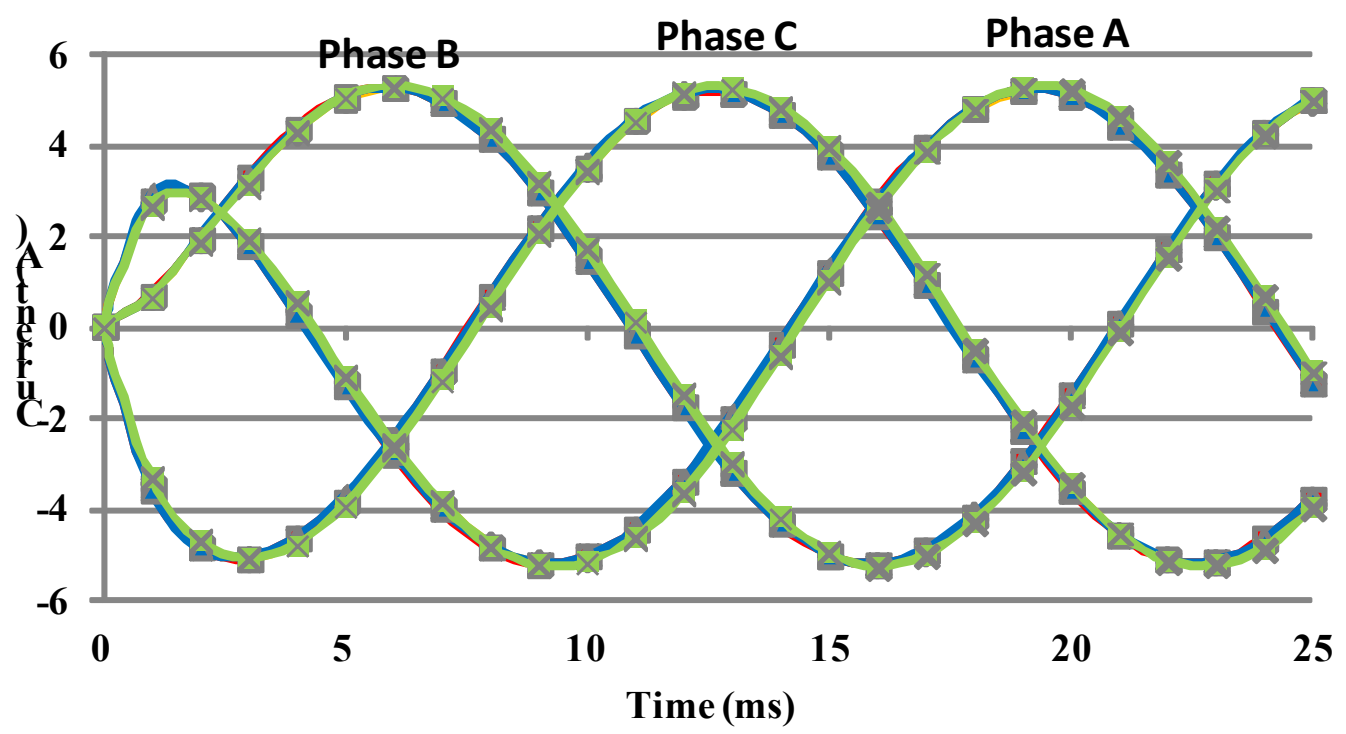

$\checkmark$ C-E Rotor $-\square$ C-I Rotor $-\Delta-$ H-E Rotor $\rightarrow-$ H-I Rotor

Fig. 18. Current waveforms from the FEA analysis for C-E Rotor, C-I Rotor, H-E Rotor and H-I Rotor.

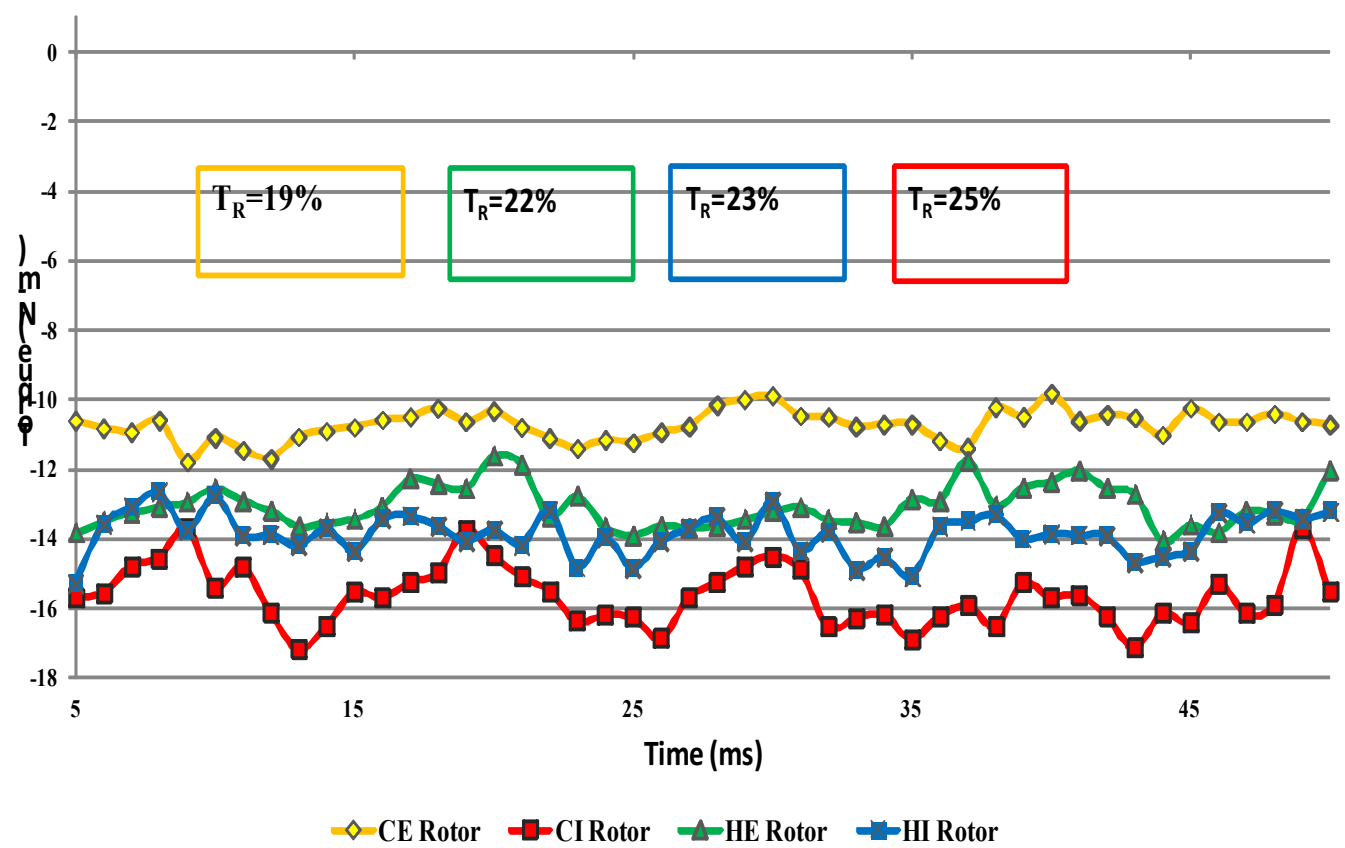

Fig. 19. Average torque and torque ripple from the FEA analysis for C-E Rotor, C-I Rotor, H-E Rotor and H-I Rotor. 


\section{RESULTS AND PERFORMANCE COMPARISON}

\section{Air Gap Magnetic Flux Comparison}

Keeping the diameter, stator coil geometry and volume of magnets same for all the four different generators, it has been observed that each generator delivers different results. Table 2 shows all parameters and output values for the four generators.

Table 2. Performance comparison between conventional ferromagnetic and non-ferromagnetic rotor machine and Halbach ferromagnetic and non-ferromagnetic rotor machine

\begin{tabular}{|c|c|c|c|c|c|c|}
\hline & Parameters Name & Unit & C-I Rotor & $\begin{array}{l}\text { C-E } \\
\text { Rotor }\end{array}$ & $\begin{array}{c}\text { H-I } \\
\text { Rotor }\end{array}$ & H-E Rotor \\
\hline \multirow{5}{*}{ 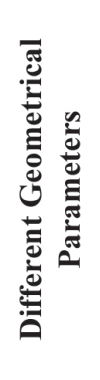 } & Magnet width to pole pitch ratio $\left(a_{P}\right)$ & - & 0.66 & 0.66 & 1 & 1 \\
\hline & Load resistance & $\Omega$ & 20.58 & 13.8 & 18.61 & 16.45 \\
\hline & Number of magnet $\left(M_{n}\right)$ & - & 12 & 12 & 24 & 24 \\
\hline & $\begin{array}{l}\text { Magnet upper width }\left(M_{W U}\right) \\
\text { Magnet lower width }\left(M_{W L}\right)\end{array}$ & $\begin{array}{l}\mathrm{mm} \\
\mathrm{mm}\end{array}$ & $\begin{array}{l}19.35 \\
29.72\end{array}$ & $\begin{array}{l}19.35 \\
29.72\end{array}$ & $\begin{array}{c}14.51 \\
22.364\end{array}$ & $\begin{array}{c}14.51 \\
22.364\end{array}$ \\
\hline & Magnet axial thickness $\left(M_{h}\right)$ & $\mathrm{mm}$ & 10 & 10 & 6.654 & 6.654 \\
\hline \multirow{14}{*}{ 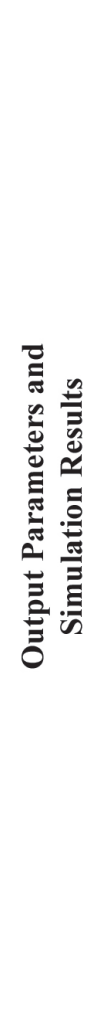 } & Rotor thickness $\left(R_{t}\right)$ & $\mathrm{mm}$ & 8 & 18 & 4 & 10 \\
\hline & Total rotor weight & $\mathrm{kg}$ & 0.527 & 0.03 & 0.38 & 0.01 \\
\hline & Total magnet weight & $\mathrm{kg}$ & 1.32 & 1.32 & 1.32 & 1.32 \\
\hline & Stator coil weight & $\mathrm{kg}$ & 1.57 & 1.57 & 1.57 & 1.57 \\
\hline & Total machine weight & $\mathrm{kg}$ & 3.42 & 2.92 & 3.27 & 2.90 \\
\hline & Airgap magnetic flux density $\left(B_{g}\right)$ & $\mathrm{T}$ & 0.7559 & 0.51 & 0.7018 & 0.59 \\
\hline & Peak voltage $\left(V_{\text {peak }}\right)$ & $\mathrm{V}$ & 107.90 & 73.86 & 100.23 & 86.90 \\
\hline & RMS voltage $\left(V_{r m s}\right)$ & $\mathrm{V}$ & 76.30 & 52.22 & 70.87 & 61.44 \\
\hline & Peak current $\left(I_{\text {Peak }}\right)$ & A & 4.73 & 4.73 & 4.73 & 4.73 \\
\hline & RMS current $\left(I_{r m s}\right)$ & A & 3.7 & 3.7 & 3.7 & 3.7 \\
\hline & Average torque $\left(T_{\text {avg }}\right)$ & $\mathrm{N}-\mathrm{m}$ & 15.7 & 10.8 & 13.01 & 13.91 \\
\hline & Torque ripple $\left(T_{R}\right)$ & $\%$ & 25 & 19 & 23 & 22 \\
\hline & Power & W & 822 & 565 & 728 & 681 \\
\hline & Power density & $\mathrm{W} / \mathrm{kg}$ & 240 & 193.5 & 222 & 235 \\
\hline
\end{tabular}


Magnetic flux density $\left(B_{g}\right)$ in the air gap is the primary and most important parameter in machine design. Because the output power comes from the $B g$, delivering from the magnets in a machine. Higher the amount of $B g$ creates higher the amount of power. In Figure 20 the comparison of $B g$ in the mid-plane of the air gap of the two opposite rotors has been shown for the four different generators. From the figure it reveals that C-I Rotor has the highest $B_{g}$, leading to the highest power. This is followed by H-I Rotor, H-E Rotor and finally C-E Rotor. The C-I rotor is better than rotors with Halbach array because the optimum $a_{P}$ enhance the magnetic flux and thereby increasing the $B_{g}$ in the air gap. However, comparing the epoxy rotors, using Halbach array is better as it strengthens the air-gap flux and reduces the leakage flux.

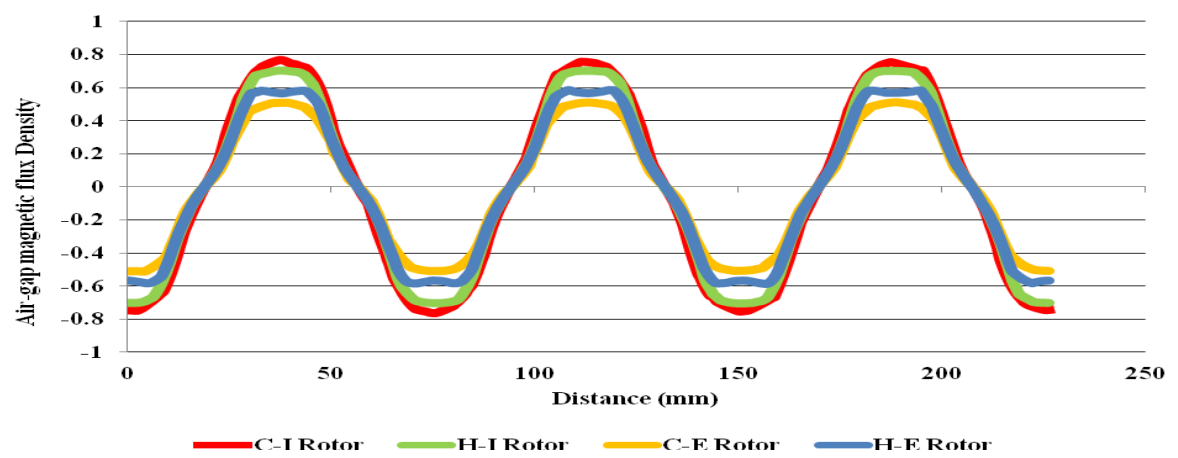

Figure 20. Magnetic flux density $(\mathrm{T})$ in the mid-level air gap for the four different generators

\section{Torque Ripple (TR) Comparison}

For designing a low speed SSDR coreless AFPM generator, torque quality is one big challenge. Torque ripple $T_{R}$ is bound to magnetic vibration and noise. In direct drive applications these vibrations transmitted directly to the load and drive shaft, which in return, affect the lifetime of the machine. Thus a minimal torque ripple is important for AFPM generator. The torque ripples of the four different topologies can be seen in Figure 19, while the FFT analysis and comparison is depicted in Figure 21 and Figure 22 respectively. Though the C-E Rotor has the lowest torque ripple of $19 \%$, due to its low average torque but for lowest power density is not compatible with the other three machines. H-E Rotor has the second lowest torque ripple. From the FFT analysis of $B_{g}$, it can see easily the presence of 5 th and 3rd harmonics are the main cause of the ripple while 3rd harmonics is not present in H-E.

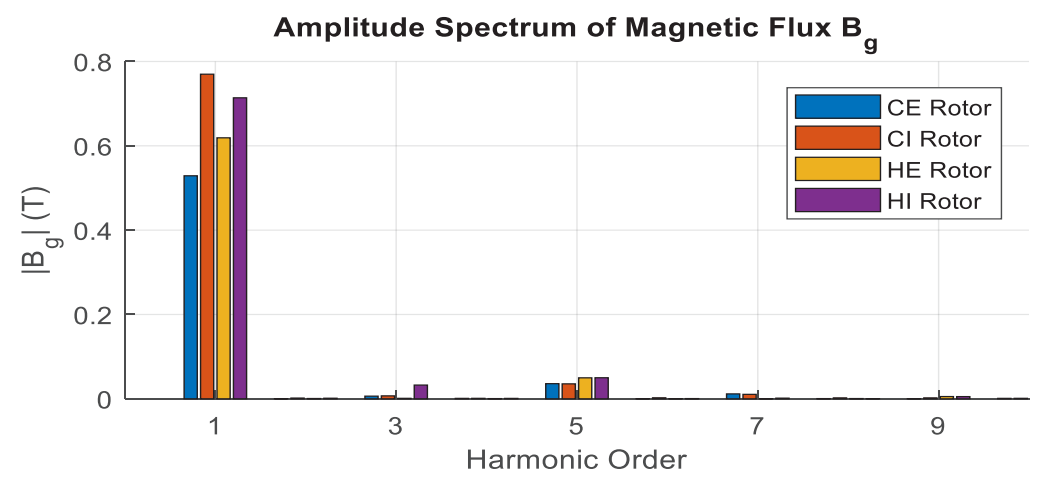

Figure 21. FFT analysis of the magnetic flux $B_{g}$ for all four topologies 


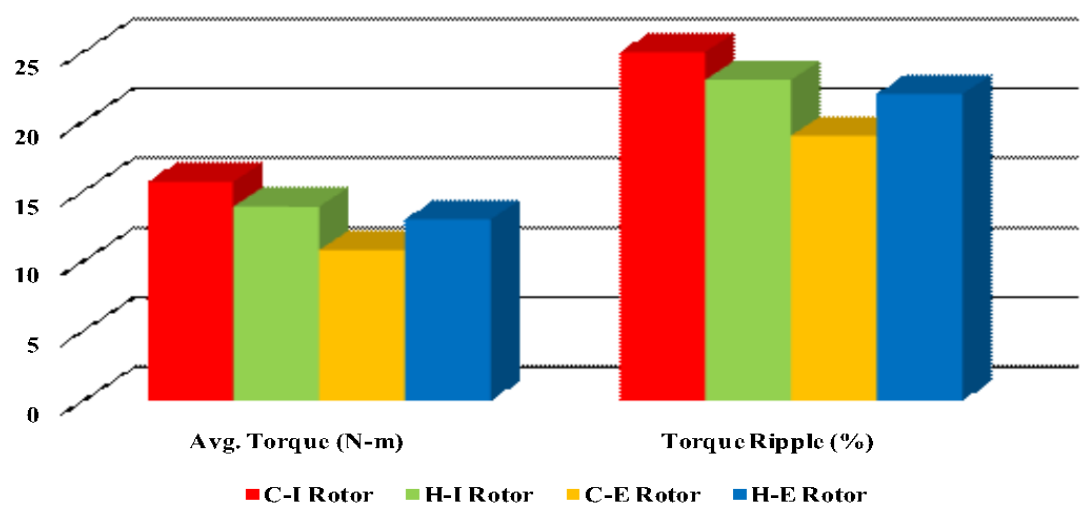

Figure 22. Comparison of average torque and torque ripple for the four different generators

\section{Power and Power Density Comparison}

Although all the generators have the same magnet volume and same machine geometry, their performance varies according to different magnets arrangement and different rotor materials. The final output power and power density for the four machines are compared as shown in table 2 and further illustrated in Figure 23. It can be seen that the C-I Rotor delivers highest power at the highest power density. Although power delivered by H-I Rotor (728 $\mathrm{W}$ ) is $13 \%$ less than the C-I Rotor $(822 \mathrm{~W})$, power density is only $5 \%$ less than the C-I Rotor generator. The C-E Rotor has the lowest power and power density with compared to the other three generators. Even though H-E Rotor gives the lower power $(681 \mathrm{~W})$ than C-I rotor, it gives comparable power density because of fully coreless, which is $2 \%$ less than the C-I Rotor. Therefore, it can be concluded that with a properly designed rotor, C-I Rotor is better than the other three topologies, but considering power density, H-E Rotor can be the alternative of C-I.

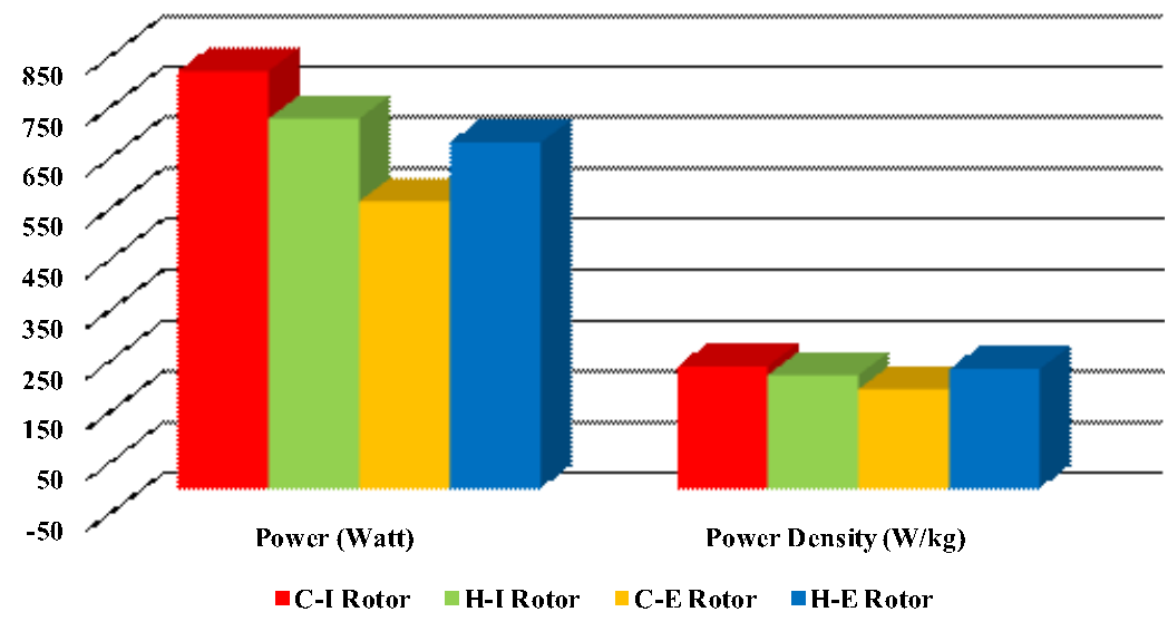

Figure 23. Comparison of power and power density for the four different generators. 


\section{CONCLUSION}

A comparison of coreless AFPM generator with different rotor structures has been discussed in this paper. Comparing the four different machines, the one with C-I Rotor is delivering the best performance. These following points can be noted for the other machines:

1. H-E Rotor is delivering the highest power density among the three. Even though the power is lower than CI rotor, it gives comparable power density, which is only $2 \%$ less comparing to the C-I Rotor.

2. H-I Rotor gives slightly better power than H-E rotor due to slight airgap flux enhanced due to the use of iron rotor. However, in terms of power density, it is slightly poorer than the $\mathrm{H}$-E rotor, delivering $5 \%$ less power density and $23 \%$ torque ripple compared to the C-I Rotor.

3.C-E Rotor has the worst performance which is $23 \%$ less power density and has the lowest torque ripple of $19 \%$ compared to other machines. This highlights the importance of iron rotor when conventional magnet array is used.

Among the three machines only H-E Rotor is a feasible alternative to the normal C-I Rotor. Despite having a lower power, generator with H-E rotor offers comparable power density, with an expected lower cost (cost of epoxy is generally lower than iron). Furthermore, H-E rotor gives the second lowest torque ripple by percentage. Considering these advantages, AFPM generator with H-E rotor, which is fully ironless, can be recommended for low power, low cost, robust and portable generator.

\section{ACKNOWLEDGMENT}

Authors recognize the financial support from University Malaya under the "Investigation on the next generation renewable energy generators based on M.O.R.E. intelligent power electronics converters"- MO0132016.

\section{REFERENCES}

Ardizzon, G., Cavazzini, G., \& Pavesi, G. (2014). A new generation of small hydro and pumped-hydro power plants: Advances and future challenges. Renewable and Sustainable Energy Reviews, 31, 746-761.

Aziz, M. S., Saleem, U., Ali, E., \& Siddiq, K. (2015). A review on bio-source, off-grid hybrid power generation systems based on alternative energy sources. Journal of Renewable and Sustainable Energy, 7(4), 043142.

Capponi, F. G., De Donato, G., \& Caricchi, F. (2012). Recent advances in axial-flux permanent-magnet machine technology. IEEE Transactions on Industry Applications, 48(6), 2190-2205.

Chan, T., \& Lai, L. (2007). An axial-flux permanent-magnet synchronous generator for a direct-coupled windturbine system. IEEE Transactions on energy conversion, 22(1), 86-94.

Charfi, S., Brahmi, N., Atieh, A., \& Chaabene, M. (2018). Energy scheduling strategy for a photovoltaic/batteries bank/diesel generator power supply system for an off-grid house. Journal of Renewable and Sustainable Energy, 10(1), 013502.

Daghigh, A., Javadi, H., \& Torkaman, H. (2017). Optimal Design of Coreless Axial Flux Permanent Magnet Synchronous Generator with Reduced Cost Considering Improved PM Leakage Flux Model. Electric Power Components and Systems, 45(3), 264-278. 
Eastham, J. F., Profumo, F., Tenconi, A., Hill-Cottingham, R., Coles, P., \& Gianolio, G. (2002). Novel axial flux machine for aircraft drive: Design and modeling. IEEE Transactions on Magnetics, 38(5), 3003-3005.

Elbatran, A., Yaakob, O., Ahmed, Y. M., \& Shabara, H. (2015). Operation, performance and economic analysis of low head micro-hydropower turbines for rural and remote areas: a review. Renewable and Sustainable Energy Reviews, 43, 40-50.

ESMAP. (2007). Technical and economic assessment of off-grid. ESMAP technical paper 121/07. Mini-grid and Grid Electrification Technologies.

Fei, W., Luk, P. C.-K., \& Jinupun, K. (2010). Design and analysis of high-speed coreless axial flux permanent magnet generator with circular magnets and coils. IET electric power applications, 4(9), 739-747.

Gieras, J. F., Wang, R.-J., \& Kamper, M. J. (2008). Axial flux permanent magnet brushless machines: Springer Science \& Business Media.

Habib, A., Che, H. S., Abd Rahim, N., Tousizadeh, M., \& Sulaiman, E.(2020). A fully coreless Multi-Stator Multi-Rotor (MSMR) AFPM generator with combination of conventional and Halbach magnet arrays. Alexandria Engineering Journal, 59(2), 589-600.

Ho-Yan, B. (2012). Design of a Low Head Pico Hydro Turbine for Rural Electrification in Cameroon.

Hosseini, S. M., Agha-Mirsalim, M., \& Mirzaei, M. (2008). Design, prototyping, and analysis of a low cost axial-flux coreless permanent-magnet generator. IEEE Transactions on Magnetics, 44(1), 75-80.

Huang, S., Luo, J., Leonardi, F., \& Lipo, T. A. (1999). A comparison of power density for axial flux machines based on general purpose sizing equations. IEEE Transactions on energy conversion, 14(2), 185-192.

Javadi, S., \& Mirsalim, M. (2008). A coreless axial-flux permanent-magnet generator for automotive applications. IEEE Transactions on Magnetics, 44(12), 4591-4598.

Javadi, S., \& Mirsalim, M. (2010). Design and analysis of 42-V coreless axial-flux permanent-magnet generators for automotive applications. IEEE Transactions on Magnetics, 46(4), 1015-1023.

Kadier, A., Kalil, M. S., Pudukudy, M., Hasan, H. A., Mohamed, A., \& Hamid, A. A. (2018). Pico hydropower (PHP) development in Malaysia: Potential, present status, barriers and future perspectives. Renewable and Sustainable Energy Reviews, 81, 2796-2805.

Kahourzade, S., Mahmoudi, A., Ping, H. W., \& Uddin, M. N. (2014). A comprehensive review of axial-flux permanent-magnet machines. Canadian Journal of Electrical and Computer Engineering, 37(1), 19-33.

Kamper, M. J., Wang, R.-J., \& Rossouw, F. G. (2008). Analysis and performance of axial flux permanentmagnet machine with air-cored nonoverlapping concentrated stator windings. IEEE Transactions on Industry Applications, 44(5), 1495-1504.

Khan, S., Bukhari, S. S. H., \& Ro, J. S. (2019). Design and analysis of a 4-kW two-stack coreless axial flux permanent magnet synchronous machine for low-speed applications. IEEE Access, 7, 173848-173854.

Kim, K.-C., Koo, D.-H., Hong, J.-P., \& Lee, J. (2007). A study on the characteristics due to pole-arc to polepitch ratio and saliency to improve torque performance of IPMSM. IEEE Transactions on Magnetics, 43(6), 2516-2518.

Latoufis, K., Messinis, G., Kotsampopoulos, P., \& Hatziargyriou, N. (2012). Axial flux permanent magnet generator design for low cost manufacturing of small wind turbines. Wind engineering, 36(4), 411-431.

Lee, M. G., Lee, S. Q., \& Gweon, D.-G. (2004). Analysis of Halbach magnet array and its application to linear motor. Mechatronics, 14(1), 115-128. 
Mahmoudi, A., Kahourzade, S., Rahim, N. A., \& Hew, W. P. (2013). Design, analysis, and prototyping of an axial-flux permanent magnet motor based on genetic algorithm and finite-element analysis. IEEE Transactions on Magnetics, 49(4), 1479-1492.

Mandelli, S., Barbieri, J., Mereu, R., \& Colombo, E. (2016). Off-grid systems for rural electrification in developing countries: Definitions, classification and a comprehensive literature review. Renewable and Sustainable Energy Reviews, 58, 1621-1646.

Messina, G., De Bella, E. T., \& Morici, L. (2019). HTS axial flux permanent magnets electrical machine prototype: Design and test results. IEEE Transactions on Applied Superconductivity, 29(5), 1-5.

Minaz, M. R., \& Çelebi, M. (2017). Design and analysis of a new axial flux coreless PMSG with three rotors and double stators. Results in Physics, 7, 183-188.

Parker, G. F. F., S.A; \& Giddens,E.P. (2017). A low head turbine for microhydropower. International Energy Journal, 15(2).

Praveen, R., Ravichandran, M., Achari, V. S., Raj, V. J., Madhu, G., \& Bindu, G. (2012). A novel slotless Halbach-array permanent-magnet brushless dc motor for spacecraft applications. IEEE Transactions on Industrial Electronics, 59(9), 3553-3560.

QI, L.-x., WANG, X.-y., DU, J.-j., Fang, Z., \& TANG, R.-y. (2006). Magnetic field analysis of disk coreless permanent magnet synchronous motor based on thickness variation Halbach array. Journal of Iron and Steel Research, International, 13, 439-443.

Rossouw, F. G. (2009). Analysis and design of axial flux permanent magnet wind generator system for direct battery charging applications. Stellenbosch: University of Stellenbosch.

Sadeghierad, M., Darabi, A., Lesani, H., \& Monsef, H. (2009). Rotor yoke thickness of coreless high-speed axial-flux permanent magnet generator. IEEE Transactions on Magnetics, 45(4), 2032-2037.

Singh, P., \& Nestmann, F. (2009). Experimental optimization of a free vortex propeller runner for micro hydro application. Experimental Thermal and Fluid Science, 33(6), 991-1002.

Tan, Y., Shen, J.-X., Jin, M.-J., \& Hao, H. (2015),Study of magnet fatigue in hybrid PM memory motors. Paper presented at the Sustainable Mobility Applications, Renewables and Technology (SMART), 2015 International Conference on.

Taran, N., Rallabandi, V., Heins, G., \& Ionel, D. M. (2018). Coreless and conventional axial flux permanent magnet motors for solar cars. IEEE Transactions on Industry Applications, 54(6), 5907-5917.

Upadhyay, P. R., \& Rajagopal, K. (2006). FE analysis and computer-aided design of a sandwiched axial-flux permanent magnet brushless DC motor. IEEE Transactions on Magnetics, 42(10), 3401-3403.

Virtic, P., Pisek, P., Marcic, T., Hadziselimovic, M., \& Stumberger, B. (2008). Analytical analysis of magnetic field and back electromotive force calculation of an axial-flux permanent magnet synchronous generator with coreless stator. IEEE Transactions on Magnetics, 44(11), 4333-4336.

Virtič, P., Vražić, M., \& Papa, G. (2016). Design of an axial flux permanent magnet synchronous machine using analytical method and evolutionary optimization. IEEE Transactions on energy conversion, 31(1), 150-158.

Williams, A. A., Upadhyay, D. R., Demetriades, G. M., \& Smith, N. P. A. (2000). Low head pico hydropower: A review of available turbine technologies. In World Renewable Energy Congress VI, 14751480.

Williamson, S., Stark, B., \& Booker, J. (2014). Low head pico hydro turbine selection using a multi-criteria analysis. Renewable Energy, 61, 43-50. 
Williamson, S., Stark, B. H., \& Booker, J. D. (2011). Low head pico hydro off-grid networks. Paper presented at the In Proceedings of the EWB-UK national research \& education conference UK

Zhu, D., Beeby, S., Tudor, J., \& Harris, N. (2013). Increasing output power of electromagnetic vibration energy harvesters using improved Halbach arrays. Sensors and Actuators A: Physical, 203, 11-19.

Zhu, Y., Chen, S., Huang, W., Wang, L., \& Ma, G. (2018). Complementary operational research for a hydrowind-solar hybrid power system on the upper Jinsha River. Journal of Renewable and Sustainable Energy, 10(4), 043309.

Zhu, Z., \& Howe, D. (2001). Halbach permanent magnet machines and applications: a review. IEE Proceedings-Electric Power Applications, 148(4), 299-308. 